\title{
Research on Fatigue Performance of PVA-ECC Under Reciprocating Action of The Wheel Pressure
}

\author{
Wang Jianjun ${ }^{1, a}$, Wang Yajun ${ }^{2, b}$, Li Yuehan ${ }^{2, c}$ \\ ${ }^{1}$ The Seventh-Engineering Corps of China Airport Construction, Baoji, 721006, China \\ ${ }^{2}$ Airport department of Air Force Service College, Xuzhou, 221006, China \\ aemail: wangjianjun-hm@163.com, bemail:wyj-1972@163.com, 'naby @163.com
}

Keywords: Airport Pavement; PVA-ECC; Reciprocating Action; Fatigue;

\begin{abstract}
Cement concrete airport pavement frequently damaged in fatigue failure caused under the effect of reciprocating wheel pressure. Repair effect by traditional materials were not effective.In this study, which fiber PVA were used as a reinforcing material, the PVA - ECC airport pavement were tested on test stand to study its anti-fatigue properties by detecting its maximum deflection value and tensile stress of bottom surface layers with different dosage of PVA. It showed that the addition of fibers PVA improved the toughness and anti-fatigue durability of pavement and this test provided a guideline for the future research. In this study, simulation experiment was carried out on the airport pavement test bench to compare the fatigue resistance of PVA-ECC panels with different fiber content by detecting its cyclic loading frequency, maximum deflection value and tensile stress of bottom under the effect of reciprocating wheel pressure.
\end{abstract}

\section{Introduction}

Airport pavement were in a state of stress and strain overlap for a long time under reciprocating wheel pressure, this effect would lead fatigue damage to pavement structure after a certain number of times. Cement concrete were used as traditional materials to repair the pavement, but the repaired surface damaged a few months later due to weak adhesion between old and new concrete bond, easily crack, poor durability and etc[1]. To avoid a similar situation, it eagerly needs to improve pavement materials and repair materials were used currently to improve the quality of pavement.

\section{Test design}

Test raw materials and the mixture ratio. P.O 42.5 cement, fly ash level 1 produced in Xuzhou power plant, local river sand whose silt content was less than $1 \%$ and fineness modulus was 2.18, domestic fiber PVA with each length of $6 \mathrm{~mm}$, Polycarboxylate super plasticizer whose water reducing rate was $30 \%$, running water. Each set of concrete mix such as shown in table 1.Panel specimen made and conserved by standard method with the size $300 \mathrm{~mm} \times 300 \mathrm{~mm} \times 50 \mathrm{~mm}$ were shown in Fig.1. Sub grade compaction degree was 95\%. Thickness of cement stabilized macadam base was $300 \mathrm{~mm}$, ordinary Portland cement $32.5 \mathrm{MPa}$ with content of $4 \%$,gravel were used in three sizes $5 \mathrm{~mm}-10 \mathrm{~mm} 、 10 \mathrm{~mm}-20 \mathrm{~mm} 、 20 \mathrm{~mm}-30 \mathrm{~mm}$ [2] with the proportion 23:41:36 and the crush value was less than $30 \%$; gradation of fine aggregate with the dosage $15 \%$ was shown in Table 2.

Table1 Concrete mix ratio[kg]

\begin{tabular}{ccccccc}
\hline NO. & cement & fly ash & sand & water & reducing agent & fiber PVA \\
\hline JZ & 786 & 296 & 627 & 454 & 14 & 0 \\
P0.5 & 786 & 296 & 627 & 454 & 14 & 6.5 \\
P1 & 786 & 296 & 627 & 454 & 14 & 13 \\
P1.5 & 786 & 296 & 627 & 454 & 14 & 19.5 \\
\hline
\end{tabular}

Table2 Gradation of fine aggregate

\begin{tabular}{cccccccc}
\hline sieve size[mm] & 4.75 & 2.36 & 1.18 & 0.6 & 0.3 & 0.15 & 0.075 \\
mass percentage[\%] & 100 & 65 & 42.3 & 27.5 & 17.9 & 11.6 & 7.5 \\
\hline
\end{tabular}




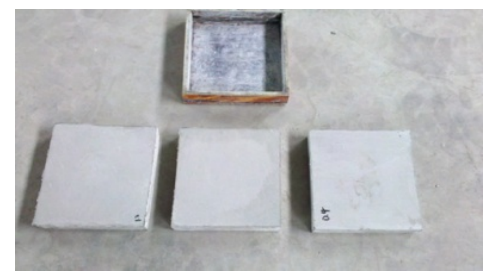

Fig. 1. Panel specimen

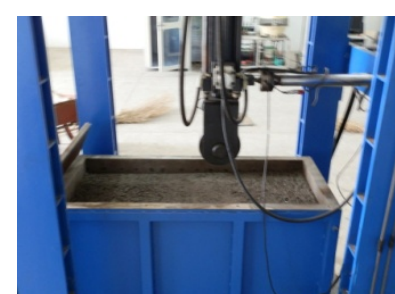

Fig. 2. Cement stabilized macadam base

Conserved by standard method seven days later, alkaline lotion containing solid content $50 \%$ was laid as seal layer material on the surface of cement stabilized macadam base shown in Fig. 2 to make the base and the panel together. Then, put the panel affixed by_strain gauges in the bottom on the base, thus preparation work was done.

Test bench KPD-01 (shown in Fig. 3)was used in this study, by simulating the wheel rolling back and forth on the surface of specimen, fatigue damage occurred in pavement could be observed. Test device was mainly composed of a host system (shown in Figure 4), hydraulic oil source system, servo control system, high voltage control system, computer data processing system and other components. Test data can be collected in real time and then test curves can be drawn.

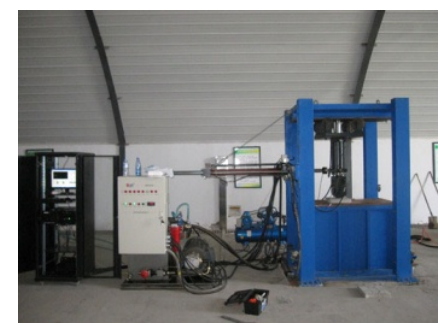

Fig. 3 Test bench KPD- 01

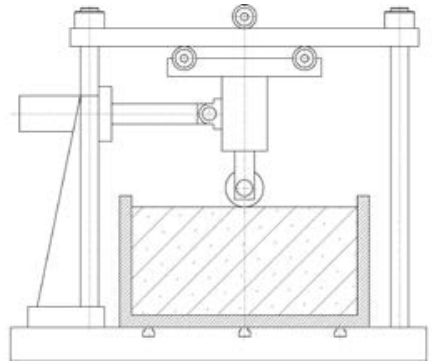

Fig.4 Host system

Test panel was set to bear a domestic aircraft wheel load, it assumed that aircraft was sliding along the middle of the pavement, contact area between tire and pavement was $848.53 \mathrm{~cm}^{2}$ with vertical stress $1.16 \mathrm{MPa}$, it meant that dynamic load on a main wheels was $98.43 \mathrm{KN}$. In accordance with relevant provisions of design specifications for airport pavement [3], the cumulative number of repeated action $N_{c}$ was 3700 within the design life 30 years. So cumulative repetition $N_{e}$ could be calculated by Equation 1 for 111000 times during that time. We set the test number of cyclic loading for 120000 times in this study.

$$
N_{e}=N_{c} \cdot t
$$

Loading on stress control way, bottom stress were collected every 1000s. Deflection value of panel was recorded automatically by test-bed. Test was completed when the number of cyclic loading up to 120000 times or the panel appeared larger cracks, then recorded the number of running at that time. Flexural tensile fatigue strength $\sigma_{p}$ for concrete pavement was defined as Equation 2 where $\sigma_{s}$ represents the design bending strength.

$$
\sigma_{p}=\sigma_{s}\left(0.944-0.077 \lg N_{e}\right)
$$

\section{Experimental results and analysis}

Tested according to the above steps, it analyzed the fatigue resistance of pavement panel from the aspects of number of fatigue damage, bottom tensile stress at failure and the maximum deflection value.

Number of fatigue failure for the specimens measured in experiment was shown in Table 3. It showed that with the increase of fiber volume ratio, the number increased correspondingly. Specimens with fiber volume ratio 1.5\% damaged after 52000 times reciprocating more than that reference specimen without any fiber. Thus instructed that compared to ordinary concrete panel fiber PVA improved their toughness and flexibility; turn their failure modes from brittle fracture 
into ductile damage, and increased the bearing capacity of the panel.

Table3 Number of fatigue failure for PVA-ECC panel with different fiber volume ratio

\begin{tabular}{ccccc}
\hline volume ratio[\%] & 0 & 0.5 & 1 & 1.5 \\
Numbers & 24000 & 31000 & 39000 & 52000
\end{tabular}

Figure 5 and Figure 6 showed the stress curve change at edge and middle bottom of the plate with loading frequency respectively. It could be find that both stress increased with the increase of the loading number of wheel. At the early stage of the loading, cement matrix and fibers joint force together, the stress was growing rapidly due to mainly stress was given priority to the former. After a certain times cycling, reference specimen damaged by lower stress for tensile strength of the cement matrix was far lower than that of fiber. But for fiber specimens, its internal cement matrix transferred stress to the fiber in the late of the loading, and then the fiber transferred stress to other non-cracking cement matrix [4], stress transferred reciprocally between each other so that the bearing time extended greatly, but the stress growth tended to slow down in the latter, eventually, fiber was pulled out because the adhesion stress between fiber and matrix was destroyed. Failure stress improved with the increase of fiber content significantly.

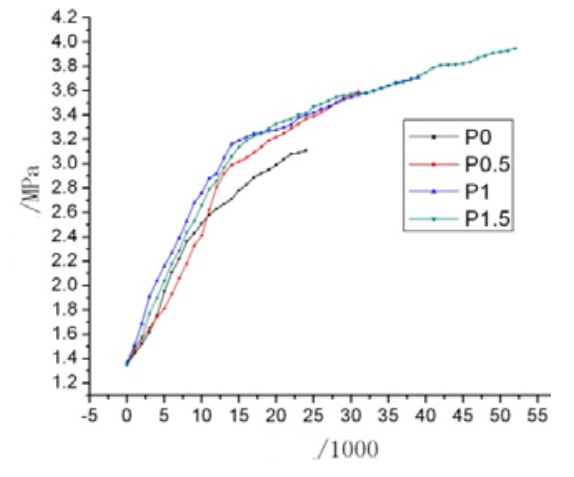

Fig. 5 Curve of edge stress

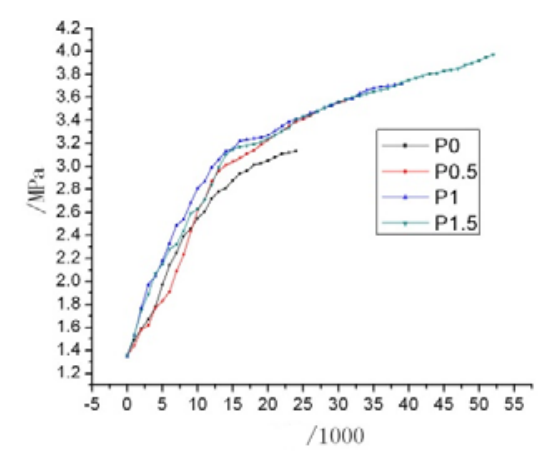

Fig.6 Curve of middle bottom stress

The measured deflection and the corresponding maximum tensile stress were shown in Table 4 . As can be seen, with increasing of fiber volume fraction, the deflection value increased gradually. It descript that the PVA fiber reinforced the tensile strength and toughness of the panel, so that it could still bear heavily load in the event of a large deflection. In practice, PVA-ECC panel can set less expansion joints or none to make the single piece with a larger area and enhance the integrity of pavement.

\begin{tabular}{ccccc} 
Table4 Deflection and the maximum tensile stress \\
\hline volume ratio[\%] & 0 & 0.5 & 1 & 1.5 \\
Deflection[ $\mu \mathrm{m}]$ & 95 & 112 & 187 & 203 \\
Edge stress[MPa] & 3.09 & 3.57 & 3.70 & 3.94 \\
Bottom stress[MPa] & 3.13 & 3.59 & 3.72 & 3.97 \\
\hline
\end{tabular}

The comparison of fatigue strength measured value with the theoretical value. The measured fatigue strength of PVA -ECC panel compared with the theoretical value calculated by the formula 2 were shown in Table 5. As can be seen, the measured fatigue strength at bottom was greater than the theoretical value when fiber volume rate was $0 \%, 0.5 \%$ and $1.5 \%$, it was on the contrary when volume rate was $1 \%$. Under normal circumstances, panel should not be destroyed in the stress. This result was mainly for the following reasons:

Table5 Comparison of fatigue strength measured value with the theoretical value

\begin{tabular}{ccccc}
\hline & P0 & P0.5 & P1 & P1.5 \\
\hline Measured value[MPa] & 3.13 & 3.59 & 3.72 & 3.97 \\
Cycles & 24000 & 31000 & 39000 & 52000 \\
Design value[MPa] & 3.09 & 3.57 & 3.70 & 3.94 \\
Theoretical value (MPa) & 3.01 & 3.56 & 3.81 & 3.95 \\
\hline
\end{tabular}


(1)Equation 2 applies to ordinary concrete pavement, but PVA - ECC and ordinary concrete are different in structure, there are certain deviation in calculation theoretical so that some coefficient need to be corrected.

(2) Specimen production may be defective, such as uneven fiber dispersion, etc.

\section{Conclusions}

The cycles increased correspondingly with the increase of fiber volume ratio, thus descript that PVA fiber enhances fatigue resistance for pavement panel. The deflection value increased gradually with increasing of fiber volume fraction, thus descript that compared to ordinary concrete the PVA fiber reinforced the toughness of the panel and made PVA-ECC panel flexible board with good deformation ability [5]. There will be some deviation for fatigue strength in actual value and the theoretical value if the ordinary concrete formula was used directly. In carrying late, fatigue strength growth of the PVA - ECC panel tended to slow down, it showed that the fiber could only improve in the fatigue strength a certain range and it remains to be further studied. Deflection of Panel is not only related to the material properties of the panel but also grassroots and soil-based properties. Performance of PVA-ECC panel measured in this test on the basis of specified grassroots and soil-based may be different with the change of prerequisite, it remains to be further studied too.

\section{References}

[1] Song Teng. Application Research on PVA-ECC in Repairing Airport Pavement[D]. Xuzhou, Air Force Service College,2010.3.

[2] Specifications for Airport Cement Concrete Pavement Mix Design (MH/T5008-2010) [M].China Civil Aviation Authority. 2010.12-13.

[3] Specifications for Airport Cement Concrete Pavement Design (MH/T5004-2010) [M].China Civil Aviation Authority. 2010.31-33.

[4] Matsumoto T,Suthiwarapirak P,and Kanda T.Mechanism of Multiple Cracking and Fracture of DFRCCs under Failure Flexure[J].Proceedings of the JCI International Workshop on Ductile Fiber Reinforced Cementations Composites (DFRCC)-Application and Evaluation (DFRCC-2002), 2002(10):259-268.

[5] Matsumoto T, Suthiwarapirak P, and Kanda T. Mechanism of Multiple Cracking and Fracture of DFRCCs under Failure Flexure [J].In: Proceedings of the JCI International Workshop on Ductile Fiber Reinforced Cementitious Composites (DFRCC)-Application and Evaluation (DFRCC-2002), 2002(10): 259-268. 